\title{
SMALL MILLERS' AND BAKERS' PERCEPTIONS OF THE LIMITATIONS OF AGRO-PROCESSING DEVELOPMENT IN THE WHEAT-MILLING AND BAKING INDUSTRIES IN RURAL AREAS IN SOUTH AFRICA
}

\author{
André Louw', Gerhard Troskie² and Mariëtte Geyser ${ }^{3}$
}

\section{ABSTRACT}

According to the Food Price Monitoring Committee (FPMC) (2003), milling and baking industries are highly concentrated, and most of the major millers are vertically integrated with bakeries. The Committee found that the baking industry is also characterised by a high level of market power, with six baking groups being responsible for 80 per cent of South Africa's bread production. Hence, this study aimed to identify the factors that restrict the development of agroprocessing in the small wheat-milling and baking industries in the rural areas of South Africa. Data was collected by means of a structured questionnaire and by conducting 15 interviews with various small wheat-milling and baking firms in the supply chain as well as with major roleplayers.

The study found that the small wheat-milling and baking industries have relatively high barriers to entry, including the ability to acquire the required capital to start operations; to establish a market; to acquire knowledge of the wheat-milling and baking industries; to uphold a well maintained infrastructure; to acquire marketing-management knowledge; and to have the necessary cash flow. The only barrier to exit deemed to prevail in the wheat-milling and baking industries is the ability to sell machinery at book value. The study also found that small-scale wheat millers and bakers felt exposed to wheat price volatility, as they had neither the cash flow nor the knowledge to counteract these price risks by way of risk-mitigating strategies available through derivative markets.

The study therefore concluded that large-scale wheat millers and bakers have a competitive advantage over their smaller counterparts, in that they have the economies of scale, necessary skills, knowledge and cash flow to overcome obstacles in a short period. Moreover, smaller wheat millers and bakers can take several months to recover from setbacks, which sometimes prove to be detrimental. The study further made some recommendations concerning these

1 Professor \& ABSA Chair in Agribusiness: Dept. of Agricultural Economics, Extension and Rural Development, University of Pretoria, Pretoria, 0002, South Africa; e-mail: andre.louw@up.ac. za, Tel: (+27 12) 420 5772, Fax: (+27 12) 4204958.

2 Dept. of Agricultural Economics, Extension and Rural Development, University of Pretoria, Pretoria, 0002, South Africa; e-mail: gerhard.troskie@up.ac.za, Tel: (+27 12) 4205740

3 D.Com Financial Management, UP: Research Unit for Environmental Sciences and Management, North-West University, Private Bag X6001, Potchefstroom, 2520, South Africa; e-mail: mariette. geyser@nwu.ac.za, Tel: (+27 82) 8212702. 
factors, in order to facilitate small-scale wheat millers' and bakers' development and expansion of production.

Keywords: developing, barriers to entry, small wheat millers and bakers, risk, financing, market structure, agribusiness, demand and supply

\section{INTRODUCTION AND BACKGROUND}

The South African wheat industry was deregulated in 1997 with the abolition of the Wheat Board. The deregulation process included the removal of the registration of bakeries, the bread subsidy, retail price controls, fixed prices for producers, millers and bakers, the regulated control of imports and exports, fixed-priced singlechannel marketing, wheat board agency agreements for handling and storage, and Wheat Board-determined quality standards (NAMC, 1999). The abolition of the Wheat Board resulted in South Africa's grain market becoming one of the most liberal in the world economy at the turn of the century (NAMC, 1999). The deregulation process also resulted in South African producers being more exposed to global markets. This ultimately resulted in higher prices and market risks for producers in the wheat industry.

In 2004, the National Agricultural Marketing Council (NAMC) conducted a study, the main goal of which was to ensure the long-term sustainability of the South African wheat industry after the deregulation process. The study found that the number of wheat milling companies in South Africa had dropped from 137 in $1996 / 97$ to 103 in 2004. The NAMC (2004) study further found that, at that time, there were 90 small mills, but that the remaining 13 large mills jointly produced 97 per cent of South Africa's wheat flour. Together, the top four wheat milling companies control approximately 87 per cent of the milling markets, according to the Food Price Monitoring Committee (FPMC, 2003).

This indicates the high level of market concentration and market power in the wheat milling and baking industry. This is also evident in the baking industry in South Africa, as it was determined that approximately 3000 bakers were registered with the Wheat Board but that approximately 80 per cent of bread production was in the hands of the four largest baking groups (FPMC, 2003). It is expected that the highest concentration of large baking groups would be mainly in urban areas and larger rural towns.

Given the high level of market concentration and power, the main goal of the study was to identify the factors that might contribute to these levels in the small wheat milling industry and, to a lesser degree, in the baking industry. The study therefore aimed to identify the factors that restrict or limit the development of the small wheat milling and baking industries, especially in the rural areas.

A study by the Industrial Development Corporation (IDC, 2010) provided 
valuable insight into the objectives of this study, by identifying factors that limited the development of agro-processing in the wheat milling industry in South Africa. Barriers to growth, key challenges facing the milling industry, a SWOT analysis (an acronym for strengths, weaknesses, opportunities and threats) as well as the market's structure and a Porter analysis on competitiveness were identified and analysed by the IDC (2010) study. It concluded that the greatest challenge facing South Africa was the attainment of food security.

Other studies reviewed included a study conducted by Mather (2005), which identified consistent patterns in the food processing sector, such as food processing small and micro enterprises (SMEs). These SMEs tended to sell and market their products outside the formal retail structures that exist in South Africa (such as Pick n Pay, Shoprite/Checkers, Woolworths and Spar). They rather supply smaller independent retail stores or other enterprises involved in a further stage of processing, and to SME food processors supplying local or regional markets. SMEs in this sector are competitive on the basis of price and/or quality, but rarely on the basis of volume. Wheat millers, for example, supply small bakeries with a guarantee that their flour is suitable for speciality baking.

A study conducted by McDonald et al. (2008), which focused on the costs and benefits of higher tariffs on wheat imports to South Africa, showed that the benefits to the wheat industry are highly concentrated but smaller than the loss of income caused in other sectors.

There is a need to understand the spatial structure of retail and service businesses in rural and urban areas. The contributions and application of the Central Place Theory (Christaller, 1933) on the impact of various forces that affect geographical concentration; on the impact of transport cost and the scale of production; and on spatial patterns of commercial activities, can provide a useful theoretical basis. Rural bakeries do not have the benefit of economies of scale in comparison with larger bakeries that mostly operate in urban areas and larger towns. Transport cost of bread could perhaps benefit the local rural bakery, depending on the procurement situation of the rural baker. For various economies of scale, these issues can impact on the production cost per loaf of bread.

With this high level of market power present in the wheat milling and baking industries, this study aimed to identify factors that restricted the development of agro-processing in these industries. Special emphasis was placed on small-scale wheat millers and bakers, as the lack of small-scale millers and bakers in rural areas was a concern. From an employment creation perspective and in the interest of the rural economy, it is vital to identify these growth barriers, or factors limiting the development of agro-processing in the rural areas.

The Department of Trade and Industry (DTI) (2011) mentions the smallscale milling industry as an area where intervention will facilitate the entry of 
small-scale maize millers in South Africa. It is expected that they will be very competitive in rural areas and that this will contribute to enterprise development and the alleviation of poverty and pressures on real wages.

\section{STUDY OBJECTIVES, DATA COLLECTION AND METHODOLOGY}

The main purpose of the study was to identify the factors that restrict development in the wheat milling and baking industries in the rural areas of South Africa. In short, the objectives of the study were to identify the critical success factors in the wheat milling and baking industries the factors that restrict or enhance competitiveness in these industries; the barriers to entry and exit; the risks in the wheat milling and baking industries; and lastly, to analyse the support structures provided to these industries. The study had a more qualitative than an empirical approach in an attempt to assist stakeholders in important issues in this small business processing sector in rural areas.

Information and data were collected by conducting interviews and using a structured questionnaire with various wheat milling and baking firms in the supply chain as well as with major role players. From the onset of the study in 2010, it was evident that wheat millers and bakers who were willing to participate and could provide accurate data would be difficult to find. The main reason for this concern was the simultaneous investigation conducted into these industries by the Competition Commission (CompCom, A). Wheat millers and bakers were therefore sceptical about making themselves available to participate in the study and provide accurate data. Originally, the study was bounded to the geographical areas of the North West and Free State provinces. However, due to the investigation and the industry role players' unwillingness to share information, the study was forced to go beyond these two provinces.

Only 15 wheat millers and bakers were willing to be interviewed and provide information relevant to the study. Of the total number of interviews conducted, 10 were with wheat millers and five with bakers. As far as possible, the study captured the views of small-, medium- and large-scale wheat millers and bakers.

The study made use of various methodologies to ensure that the information gathered was consistent and accurate. The methodologies used included the structure, conduct and performance (S-C-P) framework; the Porter model, which was used to analyse the determinants of competitiveness in the wheat processing sector; the price volatility methodology; and a risk management framework that divided the risks associated with the milling and baking industries into macro and 
micro environments.

The S-C-P framework is explained below (USAID, 2006):

Structure refers to the features of the market that influence the rivalry among buyers and sellers operating in the market. Examples include the number of buyers and sellers in the market, barriers to entry to the market, composition of the market, level of infrastructure, etc.

Conduct refers to patterns of behaviour that market participants adopt to adjust to or affect the markets in which they buy or sell. This includes price-setting behaviour, and production and marketing practices.

Performance refers to market outcomes and how the market fulfils certain social and private objectives. It encompasses price levels and stability, profit levels, costs, efficiency, as well as quantities and quality of food sold.

Figure 1 shows the dynamic nature of the S-C-P model because of its interrelationships.

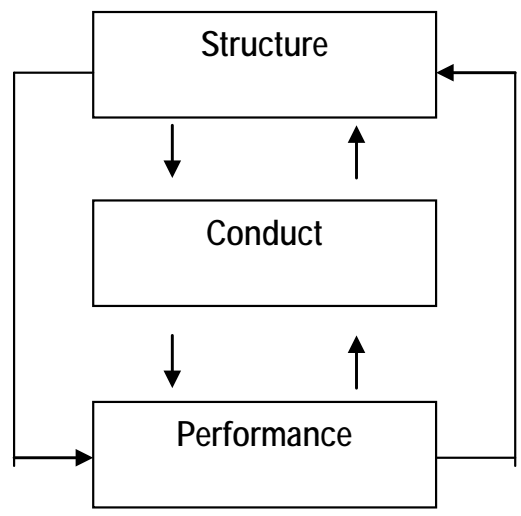

Figure 1: Dynamic S-C-P model

Source: Lutz in CAET, 2003

The S-C-P paradigm was used to analyse the various role players in the market and identify how these different elements feature in the wheat milling industry.

As mentioned, the study made use of the Porter model to analyse competitiveness in the wheat sector. Figure 2 indicates Porter's four forces that impact the ultimate profit potential of an industry. The four forces include factor conditions; firm strategy, structure and rivalry; demand conditions; and the role of the government. The signs indicate a relatively positive, neutral or negative impact on the potential profitability of the industry. 
As illustrated below, Porter's competitive platform examines the five basic competitive forces, namely, firm strategy, structure and rivalry, factor conditions, demand conditions, related and supporting industries and the role of government. The collective strength of these forces determines the ultimate profit potential of an industry.

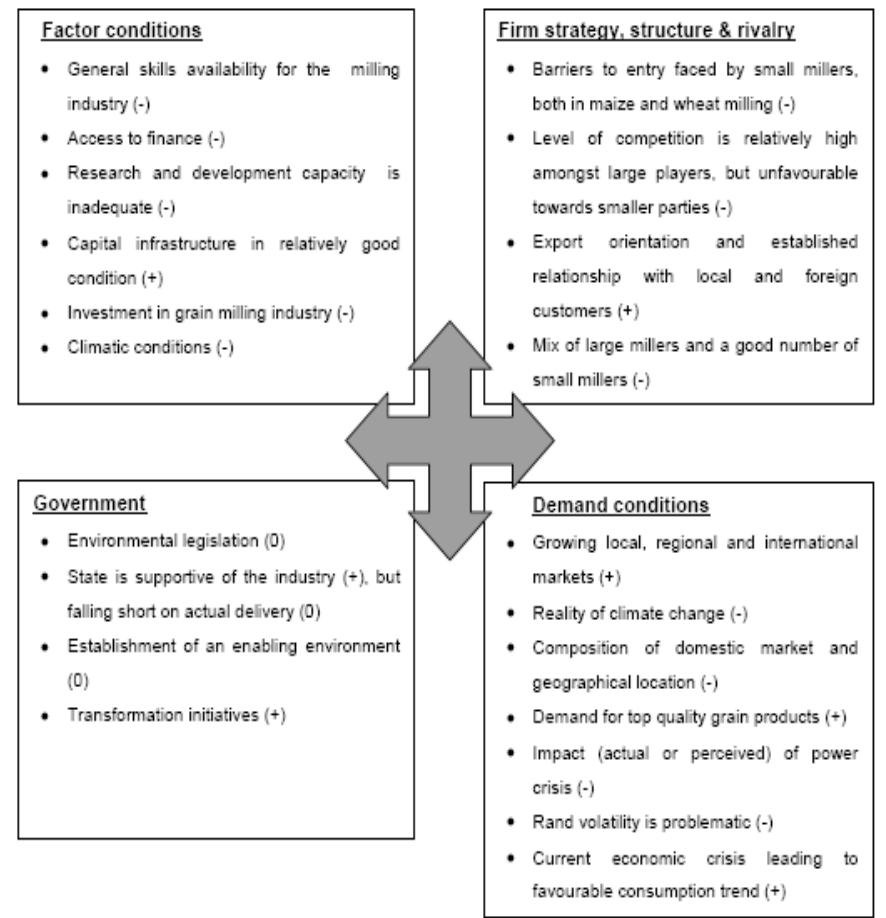

Figure 2: Porter's four forces for the milling industry, as identified by the IDC

Source: IDC (2010)

The IDC (2010) study concluded that the greatest challenge facing South Africa is the attainment of food security. This is underpinned by high population growth, high levels of poverty, logistics costs and heavy reliance on a few staple foods. The demand for wheat as a staple food is likely to be sustained for many decades to come. The milling industry will always play a vital role in addressing food security problems, provided that issues such as transportation and power supply are addressed and that the industry's competitiveness is maintained or enhanced.

For the purposes of this study, risk management was divided into a macro 
and a micro level. All identified risks that have an external impact on the daily operations of the milling industry are classified as macro risks. Macro risks can be divided into political, economic, social, technological and environmental risks (Louw, 2007). Micro risks have an internal impact on the milling industry in that these types of risks are unique to and affect the long-term sustainability of the industry. Micro risks can be divided into operational, product market, financial, input and export, and human-related risks.

\section{SOUTH AFRICAN WHEAT MARKET: OUTLINE}

A market overview of the wheat industry was conducted, with the main purpose being to identify current trends in terms of stock levels, production levels, consumption levels and international trade. This gave some background to the study, as a proper understanding of the wheat industry, as well as the milling and baking industries associated with it, is essential in order to benefit stakeholders and industry role players.

South Africa is a net importer of wheat. The reason for this is that South Africa's wheat prices are trading at import parity levels, making it more economical to import wheat products than procuring them from within the South African borders. Exports into neighbouring African countries will continue to be relatively low. The expected import and export trends are given in Figure 3 (BFAP, 2010).

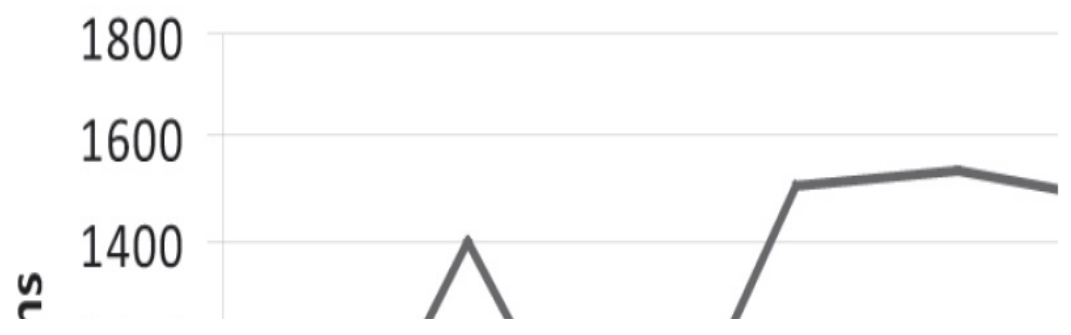

Figure 3: Wheat imports and exports of South Africa for 2006-2014

Source: BFAP, 2010 
The FPMC (2003) study analysed the wheat-to-bread value chain while, at the same time, indicating the level of market concentration within the wheat milling and baking industries. The wheat-to-bread value chain, and particularly the level of market concentration, played an important role in identifying factors that restrict development. Figure 4 represents the wheat supply chain in South Africa.

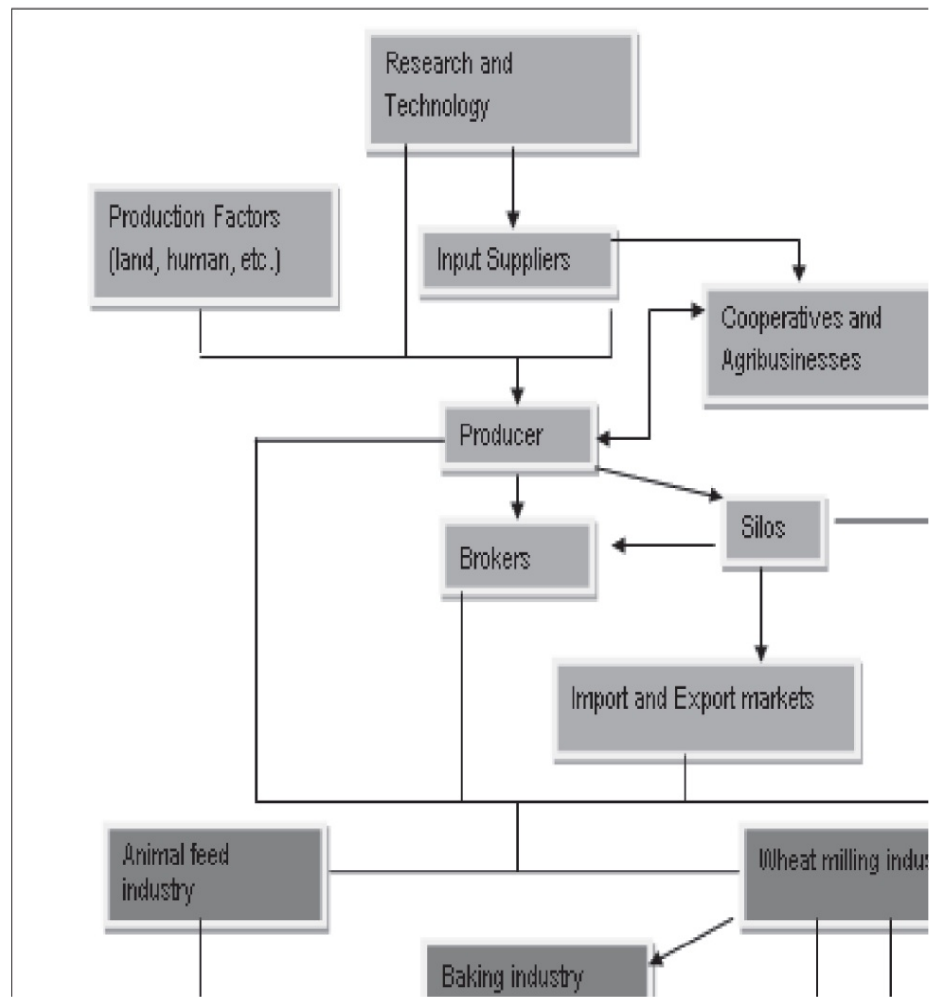

Figure 4: The South African wheat supply chain

Source: NAMC, 2009

\section{STRUCTURE OF THE INTERVIEWS}

Before the results are discussed, it is important to obtain a better understanding of the average wheat miller and baker who were interviewed. The average wheat miller interviewed had less than 10 years of experience, milled on a small scale, and had a total capital investment in machinery, buildings and vehicles of between 
R1 million and R2 million. On the other hand, the average baker interviewed fell into two categories of experience, namely, those with less than 10 years, and those with between 11 and 20 years of experience, and all of them baked on a small scale. These typical wheat millers and bakers who were interviewed suited the study perfectly as the purpose of the study was to identify the factors that restrict (small-scale) wheat millers and bakers in rural areas. Figure 5 gives a breakdown of the size and scale of the wheat millers interviewed. Out of the total number of wheat millers interviewed, 10 per cent were in the large-scale category ( $>$ than 1000 tons per day), 30 per cent represented the medium-scale category (26 to 1000 tons per day), with the remaining 60 per cent milling wheat on a small scale ( 0.5 to 25 tons per day).

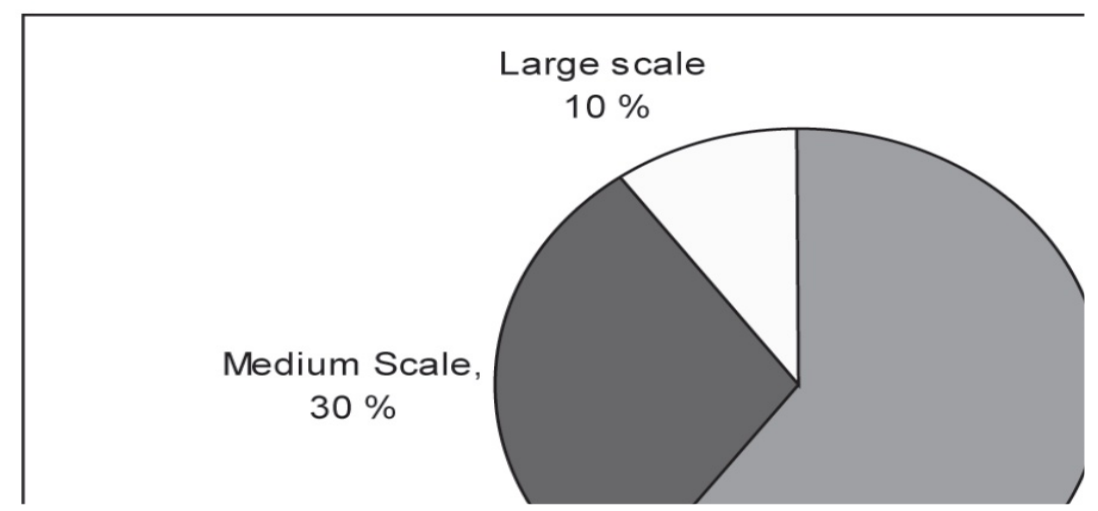

Figure 5: Size and scale of wheat millers interviewed

\section{RESULTS AND FINDINGS (CONDUCT)}

One objective of the study was to identify the level of competition in the wheat milling and baking industries. The level of competition serves as an indicator of the overall long-term sustainability of these industries. A high level of competition indicates key industry stakeholders' level of market concentration and market power behaviour. A high level of competition further enhances product differentiation and ensures that the needs of customers are met.

Of the total number of respondents, 40 per cent indicated that the level of competition within the wheat milling and baking industries was competitive (Figure 6), while the remaining 60 per cent indicated that they were highly competitive. 
This does not necessarily inhibit the entry of businesses, although it makes it less lucrative for a new business to enter such a highly competitive industry. It can be concluded that the level of competition in the wheat milling and baking industries is very high. These high levels of competition can be unhealthy, as it may restrain the long-term sustainability of small-scale wheat millers and bakers.

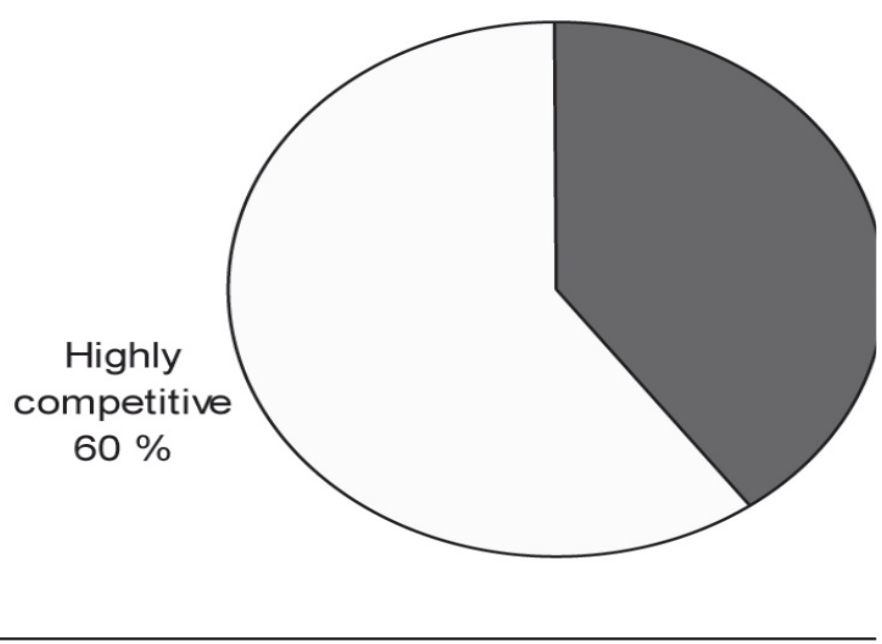

Figure 6: The level of competition perceived by wheat millers and bakers interviewed

The process of value-adding in the wheat industry is clear. However, one of the issues identified by the study that restricts development is the link between research and development. At present though, the industry's unwillingness to share information makes research laborious and difficult. Not all parties and stakeholders were willing to share information, due to a fear of some form of retaliation. Smallscale industry participants perceive access to finance as a major constraint, with the fundamental problem being the low margins associated with the industry and its high overhead costs per unit. Due to the difficulties in acquiring capital, smallscale millers find it difficult to integrate vertically in their individual businesses. A specific competitive advantage that large-scale millers have over their smallerscale counterparts is that they have easier access to finance, which they can use to integrate vertically.

Having determined that the level of competition in the industries is high, the study aimed to identify the critical success factors of the current wheat millers and bakers who remain in business despite this level of competition. The critical success factors focused on the important areas of a wheat milling and baking 
business that functions in an efficient manner for it to be successful and profitable. The highest-ranked area for a wheat milling and baking business to function efficiently is a clearly established and well-defined market. Respondents indicated that, before one can start operations, questions need to be answered with regard to who the final consumer will be, in what geographical area the product will be sold and what distribution channels will be used. In addition, the overall success of the business is also dependent on the effective management of cash flow, as procurement is mainly done on a cash basis and slow payments become a problem.

Wheat millers and bakers also indicated that, in order to be successful, knowledge and experience at management level is essential. Knowledge and experience refer to the overall management of the business as well as techniques involved in milling and baking. In the Annexure, Table 1 ranks the ten most important areas of a small wheat milling and baking business for it to be efficiently managed.

By identifying barriers to entry and exit, details of the factors that restrict development in the wheat milling and baking industries were explained. These industries were described as having relatively high barriers to entry. This statement is supported by the low number of new wheat millers and bakers who have entered these industries in recent times (National Chamber of Milling, 2010). In the Annexure, Table 2 identifies and ranks the ten most significant barriers to entry that exist in the wheat milling and baking industries.

A barrier to entry is any factor that restricts potential wheat millers and bakers from entering the market, or restricts existing wheat millers' and bakers' development. The first barrier identified by respondents was their inability to gain the necessary capital, including fixed and operational expenditure, to start operations. This can be regarded as an effect rather than a cause of the limited profitability projected by a prospective milling or baking entity, be it an individual or a firm. Milling wheat requires a significantly higher capital investment than milling maize. Start-up finance in the maize milling industry was estimated at R850 000, whereas start-up finance for a small miller in the wheat milling industry can exceed R1.5 million. These estimates only give a further indication of the industry's financial burden. Therefore, capital requirements were indicated as being the largest barrier to entry into the wheat milling and baking industry. Many small wheat millers felt that the necessary support structures were not in place for them to qualify for the necessary capital. Millers felt that obtaining capital from the government or government institutions were too time-consuming and tiresome, as it could take several years for departments to make the necessary funds available.

Establishing a market was also indicated as being a potential barrier to entry. Prospective wheat millers and bakers must exploit new market opportunities or 
develop new products. However, they indicated that there was space in the rural areas to increase wheat milling and baking capacity.

Another identified barrier to entry into the wheat millers and bakers industry was the millers' technical and management knowledge of milling and baking. A wheat miller starting a milling or baking firm must, for example, have some relevant experience and knowledge of the grades of wheat that are used for milling; of the steps and processes involved in wheat milling and baking; and of how to manage the overall wheat milling and baking business. The large-scale millers can hire specialists for each process involved in wheat milling and baking, for example, procurement, financial, and/or marketing specialists with high levels of knowledge and experience in their respective fields. On the contrary, smallerscale wheat millers are more inclined to be one-person shows, with the owner performing most of the functions required.

A barrier to exit is any factor that restricts an existing wheat miller and baker from exiting the market. All the respondents indicated that barriers to exit that exist in the wheat milling and baking industries include the ability to sell machinery at a price acceptable to the owner. If an owner of a wheat mill or bakery wants to discontinue operations, a willing buyer of the assets is required. Finding a suitable buyer for one's assets is a difficult task that could potentially restrict the wheat miller or baker from exiting the market freely. This represents a challenge, as new market entrants are limited. There is also no guarantee that the wheat miller or baker business will attain a price equal to the book value of the assets. Potential buyers could offer prices much lower than the book value of the assets, thus discouraging wheat millers or bakers from selling their assets.

South Africa is dependent on wheat imports, as it does not produce sufficient wheat quantities to meet local demand (NDA, 2010). Imports, especially imports of raw materials, and to a lesser degree exports, have an impact on the wheat milling and baking industry. The impact of imports on the respondents' businesses was more indirect, as wheat millers were more exposed to the imports of wheat products by international competitors. Imported wheat grain was sometimes not of an acceptable standard, which affected the wheat millers' final product. In terms of exports, respondents indicated that they would export their final products should the opportunity present itself, but emphasised that exporting was not their core business. It was clear that imports and exports play a very small role in the daily operations of the smaller wheat milling and baking industries.

The impact of wheat price volatility on wheat millers and bakers, especially the smaller-scale millers and bakers, was identified as being a variant factor that could restrict or limit the wheat milling and baking industries. Volatility provides a measure of the possible variation or movement in a particular economic variable that describes the tendency of a commodity, for example the wheat market, to 
move either up or down and the extent to which the anticipated move may progress. The lack of predictability and uncertainty associated with increased volatility may influence both producers and consumers. High volatility may limit the ability of processors to secure supplies and control input costs. Wheat price volatility was seen as a major risk with the largest impact on profit margins, daily operations and planning structures.

The study found that small-scale wheat millers and bakers were exposed to wheat price volatility and did not have the cash flow or knowledge to counteract wheat price risks by using the risk-mitigating strategies available on the Commodities Derivatives Market of the JSE (also known as SAFEX). Large-scale millers indicated that they did make use of SAFEX as part of their risk-mitigating strategies. This ability to offset wheat price volatility created an advantage for large-scale millers over smaller-scale millers. Large-scale millers also employ specialists in specific fields that enable them to take advantage of these opportunities.

A factor that clearly restricts the development of small-scale millers and bakers is the lack of government support in terms of the quality of infrastructure and grants that are provided. Many respondents expressed their concern about the quality of infrastructure affecting their businesses. Not having access to a properly maintained surrounding infrastructure incurred unnecessary costs and impacted on service delivery, hence decreasing the profitability of smaller-scale wheat millers and bakers. Transportation infrastructure is also a challenge for the milling industry. Many railway lines are not being maintained, which forces millers to make use of road transport, which is 30 per cent more costly. Electricity supply and prices were specifically mentioned by wheat millers and bakers as being added challenges to their businesses. As further start-up operations and expansion require more capital, many small-scale wheat millers and bakers expressed their concern over the substantial length of time it takes to qualify for much-needed funding and grants.

The constraints and challenges faced by the wheat industry (as indicated in Table 3 in the Annexure) provide valuable insight into possible factors that may restrict the competitiveness and profitability of small-scale millers and bakers. The opinions of wheat millers and bakers concerning the challenges faced by the wheat milling industry were very diverse. The level of labourers' knowledge, reliability and motivation was indicated as being a serious challenge for the industry, especially in the rural areas. Other constraints or challenges included onsite theft, the availability of wheat, high electricity costs, credit availability from commercial banks, a lack of support from the Department of Trade and Industry, deteriorating infrastructure and the level of wheat and flour imports. 
Table 4 in the Annexure summarises and ranks the areas of relative weaknesses experienced by the interviewed small wheat millers and bakers. By identifying the weaknesses of existing small wheat millers and bakers, valuable insights were obtained regarding issues that their businesses struggle with and where they require assistance.

Wheat millers' and bakers' highest-ranked weakness was found to be their inability to find loyal and motivated labourers. Other weak areas of their businesses included developing a marketing campaign, handling bad debt, acting against theft on site, and obtaining the necessary capital to expand.

There were also many threats to the wheat milling and baking industries, as identified by the respondents. The five highest-ranked threats that existed are explained in Table 5 in the Annexure.

The highest ranked threat that exists within the industry, over which wheat millers and bakers have little control, is the rise in input costs. From a development point of view, more could be done to protect the wheat milling and baking industries against this threat. Other threats include the unhealthy level of competition within the industries, the high level of imported flour experienced in recent times, the shortage of motivated and loyal labourers and theft on site.

The study also identified possible risks that have a direct impact on the wheat milling and baking industries. On-site theft was mentioned as being the biggest risk faced on a daily basis. Other risks included power outages and electricity price increases; the quality of surrounding infrastructure and logistics; defaulting on debt because of these industries doing business on a cash basis; the impact of price volatility on profits; and the level of staff skills. These facts support all the findings in the previous sections.

Table 6 in the Annexure gives an indication of the strengths of the existing wheat millers and bakers. Factors that enhance profitability and competition in the wheat milling and baking industries were perceived as a high-quality product and service offering, good management and expertise, business location and high levels of integration.

To survive, one must produce high-quality and consistent products at marketrelated prices that meet the demand and specifications of the end consumer. In addition, millers and bakers must have good management skills.

The study also identified possible opportunities in these industries, which indicate whether there is room to expand and whether these industries would be sustainable in the long term. Table 7 in the Annexure identifies possible opportunities that can be exploited by these industries.

Wheat millers and bakers felt that the biggest opportunity present in the industry is vertical integration. By vertically integrating with other areas of the wheat industry, profit risks could be mitigated and their businesses could expand. 
Some wheat millers specifically mentioned vertical integration with bakeries, as is currently the case with many large-scale wheat millers. Other opportunities include the expansion of operations in rural areas.

\section{FINANCIAL PERFORMANCE}

Evaluating the financial performance of small wheat millers and bakers provided valuable insight into the ability of the existing wheat millers and bakers to be sustainable. In order to capture the financial performance of wheat millers and bakers, the perceptions of the existing wheat millers and bakers on their turnover performance over the past five years were evaluated. Respondents were asked to indicate their performance over the past five years on a scale of very good, good, average, bad and very bad. Figure 7 indicates the perceptions of existing small wheat millers and bakers on their turnover's performance over the past five years.

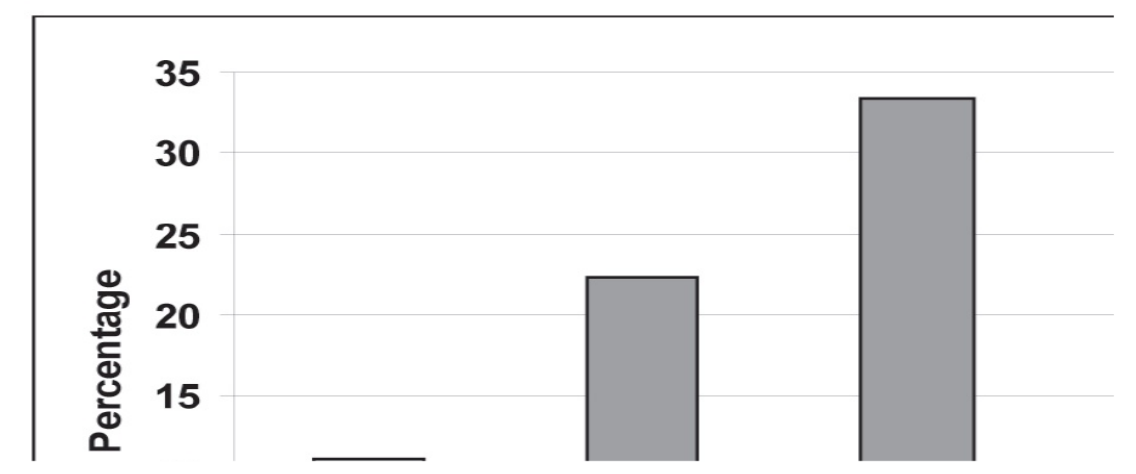

Figure 7: The perception of turnover over the past five years

The figure indicates a clear bell-shaped phenomenon, illustrating that, for some wheat millers and bakers, their turnover was very good while, for others, it was very bad. Approximately 34 per cent of respondents indicated that their financial performance over the past five years was average. Another 33 per cent of the respondents indicated that their respective turnovers over the past five years were above average. From this 33 per cent, 11 per cent indicated that their turnover was very good, while the remaining 22 per cent indicated that their turnover was good. It is worth noting that small millers and bakers indicated that there is room in the market for different sizes and scales of wheat millers and bakers. The key lies in 
identifying new market opportunities and fully exploiting these opportunities.

The last bracket of wheat millers and bakers were represented by 33 per cent of respondents. This bracket of small wheat millers and bakers indicated that their turnover over the past five years was below average and that they have experienced a drop in sales over the past few years. From this 33 per cent, 22 per cent indicated that their turnover performed badly, while 11 per cent indicated that it performed very badly. From the analysis, it was also notable that the majority of wheat millers and bakers felt that the impact of increases in input costs on their respective businesses was dramatic.

The financial performance of large-scale wheat millers and bakers was superior to that of smaller-scale wheat millers and bakers. Smaller-scale wheat millers and bakers therefore required more support from the Department of Trade and Industry and government institutions to aid in their sustainability.

However, the study found that there were only a few small bakeries left in the rural areas that were included in the study. One of the reasons for this was the increase of supermarket bakeries in small towns. Rather than for profitability, supermarkets merely viewed bakeries as an additional product line that they could offer to their customers. Bakeries focusing only on their core business therefore experienced increased competition from these supermarkets, as customer-buying behaviour changed towards a one-stop shop where they could buy all their groceries.

\section{CONCLUSIONS}

The main purpose of the study was to identify the factors that restrict the development of the wheat milling and baking industries in rural areas. A literature review was conducted to demonstrate that the study would add to the existing body of knowledge on factors that restrict the development of agro-processing, especially focusing on small entities. From the onset of the study, it was clear that conducting research within the small wheat milling and baking industries would be difficult. Finding wheat millers and bakers who were willing to share information and views was difficult with the simultaneous investigations by the Competition Commission (CompCom, B). Trust between stakeholders in the supply chain seemed to be a major obstacle. Research, flow of information and development are important cornerstones for informed policy decisions, benchmarking, and expansion and growth in any industry. A greater effort should be made to create an environment where there is trust and easy access to information can be guaranteed.

In order to identify the factors that restrict development in the small wheat milling and baking industries, one of the objectives of the study was to identify critical success factors or areas for existing small wheat millers and bakers as well as new entrants to expand. The most important critical area identified was 
the establishment of a well-defined market (end consumer) as the first crucial step for success in setting up their businesses. Other critical areas of a small wheat milling and baking business included, among others, effective management of cash flow, knowledge and know-how of wheat milling and baking, and effective management of input costs.

The impact of wheat price volatility on the profitability of smaller-scale wheat millers and bakers was also addressed. Of the respondents, 44 per cent indicated that wheat price volatility had a dramatic impact on their profitability. The majority of the small wheat millers and bakers indicated that they did not have the necessary skills and cash flow to make use of price hedging and other riskmitigating strategies. The large-scale wheat millers and bakers had an advantage over the small-scale wheat millers and bakers in this regard.

The wheat milling and baking industry is exposed to a number of risks. These risks can potentially restrict development in the industry, for example, the quality of the surrounding infrastructure and electricity supply and prices. Other risks identified included on-site theft, default on debt and the level of staff skills. All of these risks incur unnecessary costs for smaller-scale wheat millers and bakers. A factor that was clearly restricting development and affecting their business was a lack of government support in terms of quality infrastructure and grants. The low quality of infrastructure, which leads to higher costs, should be addressed by national, provincial and local governments. With regard to the level of crime and theft, active steps should be taken by government and local communities to combat crime, especially in rural areas. Existing wheat millers and bakers should be made aware of the skills development programmes available at the National Chamber of Milling, the SA Chamber of Baking and AgriSeta. The National Chamber of Milling expressed its disappointment at the extent to which government training authorities were involved in facilitating and training within the industry (National Chamber of Milling, 2010).

Another objective of the study was to identify barriers to entry and exit in the industry that also restrict development in the small wheat milling and baking industries. These barriers include capital requirements, the establishment of a market, cash flow management and the hiring of motivated and skilled labourers. Sound business knowledge was also important to enable them to take advantage of opportunities and successfully manage their cash flow, procurement and marketing campaigns. According to the South African Grain Information Service (SAGIS), any business that stores grain in silos and adds value to grain products must be registered with the Service. SAGIS could contribute to the milling and baking industries by periodically issuing reports and releasing information and statistics on the current state of small-scale wheat millers and bakers in South Africa. As mentioned in the study, capital requirements in the wheat milling and baking industries are important in start-up operations. 
The wheat milling industry can be considered a high-volume-output, lowprofit-margin industry. In order to survive, wheat millers expand by adding value to their product. This can be done by establishing bakeries, while bakers can develop their businesses into one-stop shopping experiences for customers. In general, large-scale wheat millers and bakers have a competitive advantage over their smaller-scale counterparts, in that they have the necessary skills, knowledge, cash flow and economies of scale to quickly overcome obstacles. The value chain for small wheat millers and bakers in rural areas requires further research which could benefit new entrants and current businesses in order to create employment and development opportunities in those areas. These areas also need to be identified as value chains and can differ geographically. Certain areas that could warrant further investigation are relationships in supply chains, governance in supply chains, innovation and entrepreneurship in supply chains, logistics, procurement challenges, supply chain risks and quality and assurance management.

In terms of power relations between role players, it can be concluded that the wheat milling and baking industries are highly concentrated, with the four largest milling and six largest baking companies dominating the market. Furthermore, these large milling and baking companies have a high level of vertical integration. Retailers, on the other hand, also have a relatively high degree of market power. The downside of this is that it increases barriers to entry for smaller-scale wheat millers and bakers. This pressure was also reflected in their financial performance.

Smaller businesses can, however, also be more creative. They are in a position to create a niche through branding and differentiated products in order to establish markets and address certain current challenges.

It can finally be concluded that the larger wheat millers and bakers, who mainly operate in urban areas and in large towns, have a competitive advantage over their smaller counterparts in the rural areas where there is a lack of economies of scale, finance, skills and the ability to cope with risks such as price volatility. The development and survival of wheat milling and baking in rural areas require a greater level of support through the financing of start-up businesses, training, gaining of relevant experience, etc. The process of making funds available could be expedited, that is, making it available within a reasonable period of time after application.

Although the DTI's (2011) endeavours to facilitate small-scale maize millers (and wheat millers), the barriers for small-scale businesses are significant. It will be useful if policy makers are informed by this study regarding the complexities of this sector. Other research opportunities emanating from the article are the greater focus on costs and profitability figures of small and large bakeries and millers. The theory of spatial economics and the impact of transport costs, economies of scale, market size effects and linkages are also areas that can be investigated in future. 


\section{ANNEXURE: TABLES WITH DETAILED OUTCOMES OF DIFFERENT RANKINGS}

Table 1: The critical areas of a small wheat milling and baking business as identified by the respondents

\begin{tabular}{|l|l|}
\hline AREAS & RANKING* $^{*}$ \\
\hline Well-defined market (end consumer) & 1 \\
\hline Effective management of cash flow & 2 \\
\hline Knowledge of wheat milling and baking & 3 \\
\hline Effective cost management strategy & 4 \\
\hline Procurement management & 5 \\
\hline Obtaining and managing required capital & 6 \\
\hline High level of service delivery & 7 \\
\hline Management of labour & 8 \\
\hline Wheat gristing techniques & 9 \\
\hline Well-managed marketing campaign & 10 \\
\hline
\end{tabular}

\section{*Ranked from 1-10, with 1 being the most critical area}

Table2: Barriers to entry for small wheat milling and baking industries

\begin{tabular}{|l|l|}
\hline BARRIERS & RANKING* $^{*}$ \\
\hline Obtaining the necessary capital to start operations & 1 \\
\hline Establishing a market & 2 \\
\hline Knowledge of wheat and wheat milling industries & 3 \\
\hline Sound business skills & 4 \\
\hline Well-maintained infrastructure surrounding the business & 5 \\
\hline Lack of marketing management knowledge & 6 \\
\hline Trusted relationship with suppliers and buyers & 7 \\
\hline Availability of necessary cash flow & 8 \\
\hline Location of the business & 9 \\
\hline Employing a highly-skilled labour force & 10 \\
\hline
\end{tabular}

*Ranked from 1-10, with 1 being the most significant barrier 
Table 3: The ten most significant constraints and challenges currently being experienced by small wheat millers and bakers

\begin{tabular}{|l|l|}
\hline CONSTRAINTS/CHALLENGES & RANKING ${ }^{*}$ \\
\hline Knowledge levels of labourers & 1 \\
\hline Theft taking place on and around the premises & 2 \\
\hline Availability of wheat & 3 \\
\hline Electricity supply and costs & 4 \\
\hline Credit availability from banks and support from the DTI & 5 \\
\hline Deteriorating infrastructure & 6 \\
\hline Collusion among wheat millers & 7 \\
\hline Imports of wheat and flour & 8 \\
\hline Respective cash flow positions & 9 \\
\hline Ability of large-scale millers to keep high volumes of raw material on hand & 10 \\
\hline
\end{tabular}

*Ranked from 1-10, with 1 being the most significant issue/constraint/challenge

Table 4: Weaknesses of small wheat millers' and bakers' businesses

\begin{tabular}{|l|l|}
\hline WEAKNESSES & RANKING* $^{*}$ \\
\hline Motivated, loyal labour force & 1 \\
\hline Obtaining the necessary capital & 2 \\
\hline Developing an effective marketing campaign & 3 \\
\hline Handling bad debts & 4 \\
\hline Acting against theft & 5 \\
\hline Procurement and logistics management & 6 \\
\hline High overhead costs & 7 \\
\hline Increasing milling and baking capacity & 8 \\
\hline Limiting product differentiation & 9 \\
\hline Cash flow & 10 \\
\hline
\end{tabular}

*Ranked from 1-10, with 1 being the weakest area 
Table 5: Threats to the small wheat milling and baking industries

\begin{tabular}{|l|l|}
\hline THREATS & RANKING* $^{*}$ \\
\hline Ever-increasing input costs (electricity and fuel prices) & 1 \\
\hline Unhealthy level of competition within the industries & 2 \\
\hline High levels of imported flour & 3 \\
\hline Shortage of motivated and loyal labourers & 4 \\
\hline Theft at the premises & 5 \\
\hline
\end{tabular}

*Ranked from 1-5, with 1 being the biggest threat

Table 6: $\quad$ Strengths of small wheat millers' and bakers' businesses

\begin{tabular}{|l|l|}
\hline STRENGTHS & RANKING* $^{*}$ \\
\hline High-quality product offering & 1 \\
\hline High-level service offering & 2 \\
\hline Good management team and expertise & 3 \\
\hline Good location of the business & 4 \\
\hline Low overheads maintenance & 5 \\
\hline High level of integration & 6 \\
\hline High profit-making industry & 7 \\
\hline Low barriers to entry & 8 \\
\hline Healthy level of competition within the industry & 9 \\
\hline Market-related product prices & 10 \\
\hline
\end{tabular}

* Ranked from 1-10, with 1 being the strongest area

Table 7: Opportunities identified by small wheat milling and milling respondents

\begin{tabular}{|l|l|}
\hline OPPORTUNITIES & RANKING $^{*}$ \\
\hline Vertical integration of the various businesses & 1 \\
\hline Wheat milling in rural areas & 2 \\
\hline Expansion into retail markets & 3 \\
\hline Opportunities to mill other grain types (diversification) & 4 \\
\hline Increase in milling capacity & 5 \\
\hline
\end{tabular}

*Ranked from 1-5, with 1 being the best opportunity 


\section{REFERENCES}

Bureau for Food and Agricultural Policy (BFAP). 2010. The South African agricultural baseline. Bureau for Food and Agricultural Policy 13:23-26. Available at: http://www.sagis.org.za/ (accessed 22 March 2011).

Christaller, W. 1933. Central places in Southern Germany. Jena: Fischer.

College for Agricultural Economics and Trade (CAET). 2003. Structure, conduct and performance of the vegetable sector in Pengzhou County. People's Republic of China: Ya'an, Sichuan Province.

Competition Commission (CompCom, A). 2010. Welcome to the Competition Commission. Available at: http://www.compcom.co.za/ (accessed 15 June 2010).

Competition Commission (CompCom, B). 2010. Wheat milling cartel referred for prosecution. Available at: http:/www.compcom.co.za/assets/Uploads/Attached Files/MyDocuments/ White-Maize-Milling-cartel-referred-for-prosecution.pdf (accessed 15 June 2010).

DTI. 2011. Industrial policy action plan, 2011/2-2013/4. Pretoria: Department of Trade and Industry, Republic of South Africa.

Food Price Monitoring Committee (FPMC). 2003. Final report of the Food Price Monitoring Committee. Pretoria, South Africa. In: Funke, B.T. 2006. From farm to retail: costs and margins of selected food industries in South Africa. Unpublished MSc thesis in Agriculture, University of Pretoria.

Industrial Development Corporation. IDC. 2010. An overview of the grain milling industry. Unpublished report. Johannesburg, SA.

Louw, A. 2007. Risk management: managing enterprise risks. University of Pretoria, South Africa. Unpublished.

Mather, C. 2005. SMEs in SA's food processing complex: development prospects, constraints and opportunities. TIPS working paper. Pretoria: TIPS.

McDonald, S., Punt, C., Rantho, L. \& Van Schoor, M. 2008. Costs and benefits of higher tariffs on wheat imports to South Africa. Agrekon, Vol. 47 (1):19-51. Available at: http://www. informaworld.com $/ \mathrm{smpp} / \mathrm{title} \sim \mathrm{db}=$ all $\sim$ content $=\mathrm{t} 920230520 \sim \mathrm{tab}=\mathrm{issues}$ list $\sim$ branches $=47$ v47 (accessed 24 May 2010).

National Agricultural Marketing Council (NAMC). 1999. The deregulation process: The wheat to bread value chain. Available at: http://www.namc.co.za/dnn/LinkClick.aspx?fileticket=2 U4VBiCJeO0\%3D\&tabid=72\&mid=535 (accessed 4 May 2010).

National Agricultural Marketing Council (NAMC). 2004. Strategy document for the South African wheat to bread value chain. Available at: http://www.grainmilling.org.za/ document/ WHEAT\%20Strategy\%20(April\%202004).doc (accessed 4 May 2010).

National Chamber of Milling. 2010. Interview on Wheat Project. e-mail to: Louw, A. (andre. louw@up.ac.za): 16 August 2010.

National Department of Agriculture (NDA). 2010. Abstract for Agricultural Statistics. Pretoria: NDA, South Africa.

USAID. 2006. Structure-conduct-performance and food security. Washington: FEWS NET Markets Guidance, No 2. 